Dhaka Univ. J. Biol. Sci. 22(2): 155-161, 2013 (July)

\title{
AFFECTIVE STATE OF ETHNIC COMMUNITY AS RELATED TO GENDER AND MARITAL STATUS
}

\author{
Abu Yusuf Mahmud ${ }^{1}$, A.K.M. Rezaul Karim* and S.H. Mahmud \\ Department of Psychology, University of Dhaka, Dhaka-1000, Bangladesh
}

Key words: Positive affect, Negative affect, Ethnic community, Gender, Marital status

\begin{abstract}
The study was aimed at understanding the affective state of Bangladeshi ethnic community in relation to gender and marital status. Towards this end, positive and negative affects of 103 adult indigenous persons were measured. Analysis of data in multiple regressions demonstrated that both gender and marital status are significantly associated with positive affect (Gender: $\beta=0.318$, $p<0.001$; Marital status: $\beta=0.201, p<0.05$ ) but not with negative affect. Results indicated that the indigenous males have 0.32 standard deviations increased positive affect as compared to the indigenous females and that married individuals have 0.20 standard deviations increased positive affect as compared to their unmarried counterparts. Along with previous studies the present study advances the understanding that gender and marital status inequalities in affect are not specific to a particular community; rather it is a generalized picture of all societies. In general, men possess more positive affect than females; married persons possess more positive affect than the unmarried persons.
\end{abstract}

\section{Introduction}

Psychologists have shown much interest to the study of human affect in recent decades. However, they have given little attention to the affect of indigenous community, a group having distinct cultural and social identity. This has given us incomplete understanding of the nature of human affect. Thus it is important to study the affect of indigenous people as is important to study the affect of the people of mainstream society. Affect refers to the experience of feeling or emotion as distinguished from cognition, thought, or action ${ }^{(1)}$. It is a key part of the process of an organism's interaction with environment and stimuli.

Although there have been several models of affect, the present study uses the model put forward by Watson and Tellegen(2). In their model, they proposed the twodimensional structure of affect in which both positive and negative affects were defined and measured as bipolar opposites. They also interpreted the positive and negative dimensions in terms of valence - high versus low positive affect and high versus low negative affect (Fig. 1).

*Author for correspondence: <karim.akmr.monscho06@gmail.com>. 1Department of Psychology, Dhaka College, Dhaka-1205, Bangladesh. 
Research on happiness and subjective well-being suggests a mixed picture of the relationship between positive affect and negative affect. Some studies have shown that positive affect and negative affect are inversely related(4). Other studies have demonstrated that over time, positive affect and negative affect are independent across persons, thus denying the concept that positive affect and negative affect are two opposite poles of a single hedonic dimension. For example, Wessman and Ricks ${ }^{(5)}$ conducted a study to examine the fluctuations of daily affect in a small group of students. They found that persons differed in terms of their day-to-day affective states along two basic dimensions that were independent of each other. Bradburn ${ }^{(6)}$, who made another important contribution in this area, collected data in several national samples and reported that positive affect and negative affect, when measured separately, varied independently. Thus it can be concluded that positive affect and negative affect a person experiences are unrelated to each other(7).

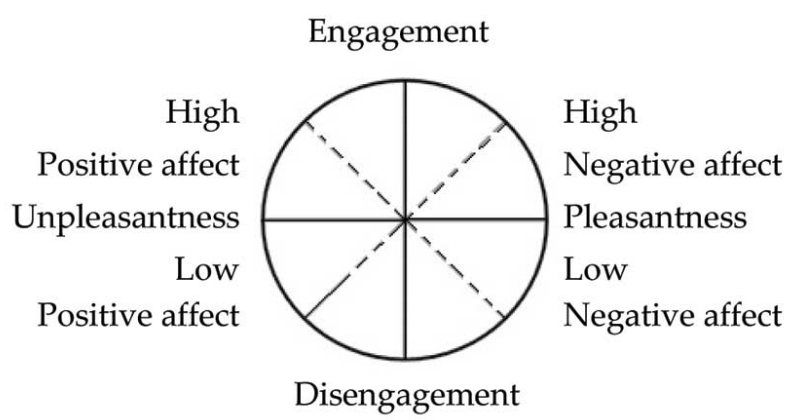

Fig. 1. Watson and Tellegen's model of the core affect (Source: Russell and Barrett( $\left.{ }^{(3)}\right)$.

In addition, relative independence of the positive affect and negative affect scientists have shown that affect or emotion can be different from male to female and from married to unmarried persons. Specifically, self-perceptions of emotional behavior have indicated that the typical female shows emotions more extremely than the typical male ${ }^{(8)}$. Lutz ${ }^{(9)}$ attributed this fact partly to the differences in socialization and partly to the differences in biological processes (e.g., birth, menstruation, specific hormonal secretion) that produce emotion. Research on socialization describes that women are socialized to be more expressive of their feelings in both verbal and non-verbal (e.g., facial expression, gesture) communications ${ }^{(9-10)}$. For example, $\operatorname{Lutz}^{(9)}$ found that women talked about the control of emotion more than twice as often as did men. Brody and Hall(11) argued that gender differences in emotions are adaptive for the differing roles that males and females play. Enactment of caretaker roles by women is likely to involve sensitivity to the needs of others, and emotional expression, whereas men's roles are less likely to emphasize emotional responsiveness ${ }^{(12)}$. Scientists have also shown that marriage has a positive 
relationship with increased positive well-being and attenuated negative outcomes for both men and women (13). Married individuals report lower rates of psychological symptoms than do the unmarried, and they seek psychological services less frequently ${ }^{(14)}$. The effects in relation to marriage and positive well-being have been obtained with reported happiness, life satisfaction, and aggregate indices of the occurrence of positive

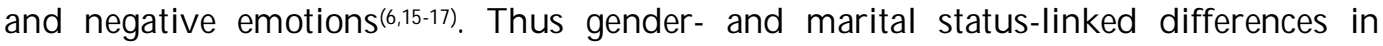
human emotion or affect are well documented. Yet, the scenario is confined to the mainstream society only. Data on the affect of indigenous people with respect to their gender and marital status are almost non-existent. That is, we still do not know whether indigenous men and indigenous women differ in emotional expressivity or affective state, nor do we know whether married and unmarried people express their affect or emotion in a different way. The present study was, therefore, designed to understand the affective state of Bangladeshi ethnic community in relation to gender and marital status.

Objectives: The specific objectives of the study were to examine whether there is (i) any gender inequality in the positive affect and negative affect of ethnic community and (ii) any marital status inequality in the positive affect and negative affect of ethnic community.

Hypotheses: The following hypotheses were formulated in the light of the past findings stated above. (i) Males would show higher positive affect than their female counterparts. (ii) Males would show lower negative affect than their female counterparts. (iii) Married persons would show higher positive affect than unmarried persons and (iv) Married persons would show lower negative affect than unmarried persons.

\section{Materials and Methods}

Participants: A total of 103 indigenous people aged 18 to 54 were selected purposively from Chittagong Hill Tracts and Greater Mymensingh. This was done without considering the proportions of different communities in indigenous population. Thus participants were selected disproportionately from 8 indigenous communities including $62.1 \%$ Chakma, $19.4 \%$ Tripura, $8.7 \%$ Marma, $5.8 \%$ Garo and $4.0 \%$ others. $71.8 \%$ of the participants were males and $28.2 \%$ were females; $18.4 \%$ of them were married and $81.6 \%$ were unmarried.

Measure: An adapted Bangla version(18) of the Positive Affect Negative Affect Scales (PANAS), originally developed by Watson et al. ${ }^{(19)}$, was used in the study. The PANAS comprises 20 mood expressing items to be rated on a 5-point Likert type scale ranging from 1 (very slightly) to 5 (extremely). Ten of the items measure Positive Affect (PA) and the other ten items measure Negative Affect (NA). Watson et al.(19) reported high internal consistencies (Cronbach's $\alpha$ ) ranging from $0.86-0.90$ for PA and $0.84-0.87$ for NA. The test-retest reliabilities over a two-month-period were also satisfactory. The original scale has good convergent (correlations with factors range from $0.89-0.95$ ) and discriminant 
validity (correlations range from 20.02 to 20.18). Significant correlations with other measures of psychological distress (e.g., Beck Depression Inventory) support its external validity ${ }^{(20)}$. Correlation between the Bangla and English versions of the full length PANAS was $0.58^{(18)}$. Correlations between the Bangla and English versions were 0.52 for $\mathrm{PA}$ and 0.77 for $\mathrm{NA}^{(21)}$. Cronbach's $\alpha$ coefficients for the Bangla version of PA and NA were 0.69 and 0.85 , respectively ${ }^{(21)}$.

Procedures: Standard data collection procedures were followed in the study. Two indigenous field workers (graduate students) were recruited and trained to administer the surveys. They visited different indigenous communities located at the Chittagong Hill Tracts and Greater Mymensingh, and contacted the participants in person. At the beginning, they briefed about the general purpose of the study to the participants and established good rapport with them. They distributed the surveys to the participants individually, asking to read the instructions printed on the questionnaires, record the socio-demographic information (e.g., gender, marital status) and respond to the items during free time. After completion of their task, the questionnaires were collected and they were thanked for participation. Thus data collection was completed approximately in 8 weeks.

Data analysis: Each participant received two scores on the scale: a PA score and an NA score. As the present study was correlational in its design, data were analyzed in multiple regression using PA and NA as the criterion variables, and gender and marital status as the predictor variables. Major assumptions of the multiple regressions (linearity, normality, homoscedasticity and multi-collinearity) were met in the present data.

\section{Results and Discussion}

Adjusted $R^{2}$ in Table 1 indicates that the model was significant and explains $12.7 \%$ of the variance in participant's PA. However, a non-significant model emerged for NA (data not shown). Standardized $\beta$ values in Table 1 show that both gender $(\beta=0.318, p<0.001)$ and marital status $(\beta=0.201, \mathrm{p}<0.05)$ were significant predictors of PA. Part correlation coefficients $\left(\mathrm{r}_{\mathrm{p}}\right)$ indicate that the unique contribution to the variance in PA was highest for gender $(10.11 \%)$ followed by marital status $(4.04 \%)$. Thus the study demonstrated that gender- and marital status contributes to the positive affect (PA) but not to the negative affect (NA). Specifically, results indicated that males have 0.32 standard deviations increased positive affect as compared to females, but no corresponding difference was observed in negative affect. The findings support the first hypothesis but not the second one. The results are fairly consistent with a number of past studies in the mainstream society showing that men and women differ in yielding certain positive and negative feelings. For example, men of the mainstream society report more positive feelings than women, which have been explained by the differences in social position, household income, and other gender inequalities in the family and workplace ${ }^{(22)}$. Present authors 
argue that like women of the mainstream society women of the ethnic community also experience discrimination or differential treatments in every sphere of their lives. For example, they experience less educational opportunities, less participation in decision making, family and social activities, higher financial disparity etc. All these together might lead to lower positive affect in the indigenous women. However, this should not be necessarily compensated by a higher negative affect as the negative affect and positive affect are independent of each other ${ }^{(5-6,23)}$. Thus, positive affect and negative affect are possibly two different constructs and a difference in one should not necessarily be accompanied by a difference in another.

Table 1. Regression of PA on gender- and marital status.

\begin{tabular}{|c|c|c|c|c|c|c|c|}
\hline \multirow[b]{2}{*}{ Predictor variables } & \multicolumn{2}{|c|}{$\begin{array}{c}\text { Unstandardized } \\
\text { coefficients }\end{array}$} & \multirow{2}{*}{$\frac{\begin{array}{c}\text { Standardized } \\
\text { coefficients }\end{array}}{\beta}$} & \multirow[t]{2}{*}{$\mathrm{t}$} & \multirow[t]{2}{*}{$\mathrm{p}$} & \multirow[t]{2}{*}{$r_{p}$} & \multirow[t]{2}{*}{$\mathrm{r}_{\mathrm{p}}{ }^{2} \times 100$} \\
\hline & $\mathrm{B}$ & SE & & & & & \\
\hline (Constant) & 30.932 & 1.173 & & 26.36 & 0.000 & & \\
\hline${ }^{1}$ Gender $(\mathrm{M})$ & 4.629 & 1.348 & 0.318 & 3.434 & 0.001 & 0.318 & 10.11 \\
\hline${ }^{2}$ Marital Status (Ma) & 3.394 & 1.563 & 0.201 & 2.172 & 0.032 & 0.201 & 4.04 \\
\hline
\end{tabular}

Adjusted $\mathrm{R}^{2}=0.127\left(\mathrm{~F}_{2,100}=8.405, \mathrm{p}<0.001\right)$. ' $\mathrm{C}$ Gender $(\mathrm{M})$ was used here as a dummy variable coded as ' 1 ' or ' 0 '. ' 1 ' stands for a membership of the male category and ' 0 ' stands for a non-membership of the male category. If ' 1 ' changes to ' 0 ' the variable switches to Gender (F), i.e., female. ${ }^{2}$ Marital Status (Ma) was used as a dummy variable coded as ' 1 ' or ' 0 '. ' 1 ' stands for a membership of the married category and ' 0 ' stands for a nonmembership of the married category. If ' 1 ' changes to ' 0 ' the variable switches to Marital Status (Un), i.e., unmarried.

Like gender, marital status was strongly and positively associated with the participants' positive affect only $(\beta=0.201, \mathrm{p}<0.05)$. Results indicated that married indigenous people have 0.20 standard deviations increased positive affect as compared to their unmarried counterparts. However, it did not show any corresponding difference in negative affect. The findings support the third hypothesis but not the fourth one. The results echo the findings of the past studies. Researchers have documented a wide range of benefits from marriage which leads to better physical and psychological health e.g., less substance abuse and less depression ${ }^{(24)}$. Studies have shown that marriage goes in line with higher happiness levels(25-26). In general, married women are happier than unmarried women, and married men are happier than unmarried men. Stutzer and Frey(24) demonstrated that married persons have greater subjective well-being than persons who have never been married or had been divorced, separated or widowed. Married women and married men tended to possess similar levels of subjective wellbeing ${ }^{(24)}$. Marriage provides additional sources of self-esteem by releasing from stress, and gives more life satisfaction. Married people have a chance to enjoy supportive intimate relationship, and suffer less from loneliness ${ }^{(24)}$. 
As stated earlier and above the past studies have shown gender and marital status inequalities in the affect of the people of mainstream society. The present study advances our understanding that gender and marital status inequalities in affect are not specific to a particular community; rather it is a generalized picture of all societies. That is, men possess more positive affect than females; married persons possess more positive affect than the unmarried persons.

Some inconsistency is noticeable in the present study. That is, gender or marital status has no contribution to the negative affect, a finding contrary to the finding for positive affect. This was unexpected and cannot be explained by the present data. The study has also some inherent limitations. For example, it cannot explain a large proportion of the variance in positive affect. To exclude such limitations, further studies can be carried out on a large scale sample comprising all types of tribes from different parts of Bangladesh. This study recruited participants from Chittagong Hill Tracts and Greater Mymensingh. Yet, the findings are important because a big proportion of the society is female even in ethnic community. So, psychologists, counselors, and other mental health professionals should give special attention to maintain positive affect among indigenous women, as they do with women of the mainstream society. The present findings also bring for the unmarried indigenous adults an important message that marriage can help foster positive affect and therefore be beneficial for mental health.

\section{References}

1. Huitt W 2003. The affective system. Educational Psychology Interactive. Valdosta, GA: Valdosta State University. Retrieved (17/10/2012) from http://www.edpsycinteractive.org/ topics/affect/affsys.html.

2. Watson D and A Tellegen 1985. Toward a consensual structure of mood. Psy. Bull. 98: 219-235.

3. Russell JA and LF Barrett 1999. Core affect, prototypical emotional episodes, and other things called emotion: dissecting the elephant. J. Personality and Soc. Psychology 76(5): 805-819.

4. Kammann R, J Barter, R Irwin and G Dixon 1979. Properties of an inventory to measure happiness and psychological health. N. Z. Psychologist 8: 1-9.

5. Wessman AE and DF Ricks 1966. Mood and Personality. New York: Holt. Rinehart \& Winston.

6. Bradburn NM 1969. The Structure of Psychological Well-Being. Chicago: Aldine.

7. Diener E, RJ Larsen, S Levine and RA Emmons 1985. Intensity and frequency: dimensions underlying positive and negative affect. J. Personality and Soc. Psychology 48: 1253-1265.

8. Johnson JT and GA Shulman 1988. More alike than meets the eye: perceived gender differences in subjective experience and its display. Sex Roles 19: 67-79.

9. Lutz CA 1996. Engendered emotion: gender, power, and the rhetoric of emotional control in American discourse. In: The Emotions (Harre R and WG Parrott Eds.), London: Sage. pp. 151-170. 
10. Haviland JM, and AS Walker-Andrews 1992. Emotion Socialization: A view from development and ethology. In: Handbook of Social Development: A Lifespan Perspective (Van Hasselt VB and M Hersen Eds.), New York: Plenum. pp. 29-49.

11. Brody LR and JA Hall 1993. Gender and emotion. In: Handbook of Emotions (Lewis M and JM Haviland Eds.), New York: Guilford. pp. 447-460.

12. Grossman M and W Wood 1993. Sex differences in intensify of emotional experience: A social role interpretation. J. Personality and Soc. Psychology 65: 1010-1022.

13. Wood W, N Rhodes and M Whelan 1989. Sex differences in positive well-being: A consideration of emotional style and marital status. Psy. Bull. 106(2): 249-264.

14. Gove WR 1972. The relationship between sex roles, marital status, and mental illness. Social Forces 51: 38-44.

15. Glenn ND 1975. The contribution of marriage to the psychological well-being of males and females. J. Marriage and Family 37: 594-600.

16. Gove WR, M Hughes and CB Style 1983. Does marriage have positive effects on the psychological well-being of the Individual? J. Health and Soc. Behavior 24: 122-131.

17. Haring-Hidore MH, WA Stock, MA Okun and RA Witter 1985. Marital status and subjective well-being: A research synthesis. J. Marriage and Family 47: 947-953.

18. Illyas QSM 2002. Bengali version of the positive and negative affect schedule. Unpublished Manuscript, Dhaka: Department of Psychology, University of Dhaka.

19. Watson D, LA Clark, A Tellegen 1988. Development and validation of brief measures of positive and negative affect: The PANAS scales. J. Personality and Soc. Psychology 54: 1063-1078.

20. Trief PM, CL Himes, R Orendorff and RS Weinstock 2001. The marital relationship and psychosocial adaptation and glycemic control of individuals with diabetes. Diabetes Care 24: 1384-1389.

21. Illyas QSM and AU Huque 2006. Bengali version of the positive and negative affect schedule. Unpublished Manuscript, Dhaka: Department of Psychology, University of Dhaka.

22. Simon RW and LE Nath 2004. Gender and emotions in the United States: do men and women differ in self-reports of feelings and expressive behavior? Amer. J. Sociology 109(5): 11371176.

23. Dienner E and RA Emmons 1984. The Independence of positive and negative affect. J. Personality and Soc. Psychology 47: 1105-1117.

24. Stutzer A and BS Frey 2006. Does marriage make people happy, or do happy people get married? J. Socio-Economics 35: 326-347.

25. Diener E, CL Gohm, EM Suh and S Oishi 2000. Similarity of the relations between marital status and Subjective well-being across cultures. J. Cross Cul. Psychology 31: 419-436.

26. Stack S and JR Eshleman 1998. Marital status and happiness: A 17-nation study. J. Marriage and Family 60(2): 527-536.

(Manuscript received on 14 April, 2013; revised on 11 June, 2013) 